\title{
Specific Varicella-Related Complications and Their Decrease in Hospitalized Children after the Introduction of General Varicella Vaccination: Results from a Multicenter Pediatric Hospital Surveillance Study in Bavaria (Germany)
}

\author{
Christine Hagemann · Alexander Krämer • Veit Grote • \\ Johannes G. Liese · Andrea Streng
}

Received: August 20, 2019 / Published online: October 31, 2019

(C) The Author(s) 2019

\begin{abstract}
Background: Universal varicella vaccination (UVV) for children introduced in Germany in 2004 resulted in a significant overall decline of varicella-related hospitalizations (VRHs). We investigated the incidence of specific types of varicella-related complications (VRCs) in hospitalized children and the impact of UVV on VRCs during the first 7 years of UVV.

Methods: Children $<17$ years of age hospitalized with an ICD-10-based (International Classification of Diseases, 10th Revision) discharge
\end{abstract}

Enhanced Digital Features To view enhanced digital features for this article go to https://doi.org/10.6084/ m9.figshare.9994730.

Electronic supplementary material The online version of this article (https://doi.org/10.1007/s40121019-00273-6) contains supplementary material, which is available to authorized users.

C. Hagemann · J. G. Liese · A. Streng

Department of Pediatrics, University Hospital of

Würzburg, Josef-Schneider-Str. 2, 97080 Würzburg,

Germany

C. Hagemann · A. Krämer ( $₫)$

School of Public Health, Bielefeld University, Universitätsstr. 25, 33615 Bielefeld, Germany e-mail: alexander.kraemer@uni-bielefeld.de

V. Grote

Dr. von Haunersches Children's Hospital, University of Munich, Lindwurmstr. 4, 80337 Munich,

Germany diagnosis of varicella were identified as VRH in pediatric hospitals in Bavaria by annual standardized data queries of the hospital databases (2005-2011). For each VRH, the hospitals reported basic demographic data, duration of hospital stay, all diagnostic and procedural codes, and outcome. VRCs were reported overall, per year, and by immune status. Complication rates were calculated as mean number per complication category per hospital and per year; VRC trends over time were assessed by linear regression.

Results: Between 78\% (2005) and 61\% (2011) of Bavarian hospitals participated and reported a total of 1263 VRHs. Specific VRCs were reported in 954 (76\%) children. Complication rates per hospital and year decreased from 6.7 [95\% confidence interval (CI): 5.1-8.3] in 2005 to 1.5 (95\% CI: $0.8-2.3)$ in 2011 , with the strongest reduction of $90 \%$ in children $<5$ years of age from 5.3 (95\% CI: 4.0-6.6) in 2005 to 0.5 (95\% CI: 0.1-0.9) in 2011. Significant decreases were observed for children with upper respiratory tract (URT, by 97\%), lower respiratory tract (LRT, by $90 \%$ ), skin (by $81 \%$ ), gastrointestinal (by 78\%), and neurologic (by 65\%) VRCs. Forty-eight children with VRCs were immunocompromised; their annual rate decreased by $87 \%$.

Discussion: Corresponding to increasing varicella vaccination coverage in the population, the incidence of VRC decreased by $77 \%$ from 2005 to 2011, with the most substantial decrease in the target group for UVV. 
Conclusion: Within 7 years, UVV in Germany led to a decrease of about $77 \%$ of all types of VRCs, with the highest reductions observed for VRCs of the respiratory tract.

Keywords: Complication; Hospitalization; Immunocompromised; Pediatric; Postvaccination period; Varicella

\section{Key Summary Points}

\section{Why Carry out This Study?}

A decline in burden of pediatric varicella was observed in all countries after implementation of universal varicella vaccination (UVV), including Germany.

However, impact of UVV on different varicella-related complication (VRC) categories in children hospitalized with varicella is unknown in Germany to date.

\section{What Was Learned from the Study?}

Complication rates per hospital and year in children $<17$ years declined by $77 \%$ from 6.7 [95\% conficence interval (CI): 5.1-8.3] cases per hospital in 2005 to 1.5 (95\% CI 0.8-2.3) cases in 2011. Highest reduction in cases was observed in children below 5 years (by 90\%), the target group for UVV.

Gastrointestinal complications declined by $78 \%$ from 2005 to 2011 , neurologic complications by $65 \%$, skin complications by $81 \%$, upper respiratory tract complications by $97 \%$ and lower respiratory tract complications by $90 \%$.

UVV can significantly reduce the burden of varicella including societal costs.

\section{BACKGROUND}

The varicella zoster virus (VZV) is highly contagious, usually resulting in a self-limiting, mild, febrile, exanthematous childhood infection in healthy children. Especially immunocompromised children are at risk of severe disease, but even in previously healthy children infections may result in varicella-related hospitalizations (VRH) due to potentially severe varicella-related complications (VRCs) [1-3]. In a German study on varicella-related complications in the pre-vaccination era, neurologic $(25.4 \%)$, skin-related $(23.2 \%)$, and gastrointestinal $(15.0 \%)$ complications were most frequently reported among immunocompetent children $<17$ years, whereas in immunocompromised children lower respiratory tract (LRT, $37.5 \%)$, hematologic (31.3\%), and gastrointestinal $(25.0 \%)$ complications were most frequently observed [1]. The incidences of VRH [4] and of the different categories of VRCs, however, vary widely among studies and countries, probably reflecting differences in region, varicella vaccination coverage, population structures, and public health systems $[1,5,6]$.

In Germany, varicella incidence in the community was estimated as 930 per 100,000 inhabitants during the pre-vaccination era [7] and the burden of VRH as 14.1 per 100,000 children $<16$ years of age [1] with an average of five varicella-related fatalities per year [8]. Universal varicella vaccination (UVV) was implemented in Germany for all children aged 11-14 months with a one-dose schedule in 2004 [9] and with a second dose at 15-23 months in 2009 [10]. Monovalent (V) and since 2006 tetravalent measles-mumps-rubella-varicella (MMRV) vaccines are both available in Germany. UVV was well accepted, with one-dose vaccination coverage of $43 \%$ for children $<2$ years of age born in 2004 to $87 \%$ in children born in 2009 and resulted in a strong decline of pediatric VRH overall [11].

In Bavaria, the second largest German Federal State, varicella vaccinations and their impact were studied in the frame of the 'Bavarian Varicella-Surveillance Project' [12-18]. Similarly to other regions in Germany until 2011, the coverage for first-dose varicella vaccination in children aged 18-36 months increased in the two observed Bavarian regions to $69 \%$ and $83 \%$, respectively [12-14]. Corresponding to the observed increase in coverage, 
the estimated incidence of pediatric VRH of 13.3 and 16.8 per 100,000 children $<17$ years of age in Bavarian hospitals in 2005 and 2006 continuously decreased in the following years to 4.8 in 2011 [16].

Thus far, only limited data are available from Germany and other countries on the magnitude of UVV's impact on different types of VRC in children [19] and are mostly restricted to specific complications, such as the decrease of neurologic VRC published previously [16] by our group. In the current article, we describe all types of VRCs observed in children with VRH within the 'Bavarian Varicella Surveillance Project' and compare their decrease during the first 7 years of UVV.

\section{METHODS}

As part of the 'Bavarian Varicella Surveillance Project,' all 37 pediatric hospital wards in Bavaria, covering an annual pediatric population of about 2 million children, were invited to participate [16]. From 2005 to 2011, participating hospitals provided each year's standardized, anonymized data on all children with a varicella-related ICD-10 (International Classification of Diseases, 10th Revision) code.

VRHs were identified by using a pre-specified algorithm with the following inclusion criteria: children $<17$ years of age at admission; at least one varicella-related ICD-10 code (B01.0-B01.9) as the main or any secondary diagnosis at discharge; stationary hospitalization for at least 1 day within the observation period from 1 January 2005 to 31 December 2011.

The hospitals reported basic demographic data, month and year of hospital admission, duration of hospital stay, all ICD-10 codes (primary and secondary), and all procedural codes (OPS). For each VRH, documented ICD-10 discharge codes indicating VRC were classified using pre-specified diagnosis-related categories of complications [1]: neurologic [16], gastrointestinal, skin, reactive arthritis, lower/upper respiratory tract (LRT/URT), hematologic, systemic bacterial, coagulation complication and related sequelae, and other complications. Codes indicating underlying chronic conditions were allocated to previously described categories [16]. Immunocompromised children were identified by ICD-10 codes indicating malignancies or potentially relevant neoplasms (C00-C97, D37-D48), immunodeficiency disorders (D80-D89) and HIV/AIDS (B20-B24, Z21), chronic juvenile arthritis (M08), nephrotic syndrome (N04), or a code indicating a transplanted organ or tissue (Z94). For further details on the study setting and data collection, see Streng et al. $[16,18]$.

\section{Ethical Considerations and Data Protection}

Approval was obtained from the Bavarian Data Protection Office (Munich) and the Ethics Committees of the Medical Faculties at the University Hospitals in Munich and Würzburg. The participating hospitals reported only anonymized data.

\section{Statistical Analysis}

Data were collected from all hospitals using Microsoft Excel tables and were analyzed with SPSS version 25.0 (SPSS Inc., Chicago, IL). Results of descriptive analyses were reported as absolute numbers with percentages or as median values with interquartile range (IQR). Data were compared using Pearson's $\mathrm{Chi}^{2}$ test or Fisher's exact test for categorical data and the Mann-Whitney $U$ test for continuous data. Complication rates per age group and per complication category were calculated as mean number of patients per hospital per year to account for the different numbers of participating hospitals per year. The number of patients per age group or per category was divided by the number of participating hospitals in the respective year (between 22 and 29 hospitals per year participated in the study; for further details refer to Supplementary Table 1). Explorative univariate linear regression analyses were employed to assess VRC trends over time. Mean number of VRCs per hospital per year was entered as dependent variable and year of hospitalization as independent variable. Analyses were stratified by age group and by type of 
complication. Significance level was defined as $p<0.05$ (two sided).

\section{RESULTS}

\section{Characteristics of Patients with Varicella- Related Hospitalizations (VRH)}

From 2005 to 2011, 22-29 hospitals per year (61-78\% of all Bavarian pediatric hospitals, representing about $80-87 \%$ of pediatric hospital beds) participated in the study. Overall, 1263 children with VRH were reported (Table 1; $54.6 \%$ male patients; median age 3 years, IQR 1.0-5.0). Children $<5$ years of age represented the largest group of VRH $(67.8 \%)$, whereas only few children were aged 10-16 years (6.0\%). Mean duration of hospital stay was 3 days (IQR: 2.0-6.0). An underlying chronic medical condition was reported in 270 patients $(21.4 \%)$; most common were malignancies/hematologic disorders/disorders of the immune system $(8.9 \%)$, and neurologic disorders $(3.8 \%)$. Of all 1263 children with VRH, 5 (0.4\%) showed particularly severe disease requiring treatment in a pediatric intensive care unit (PICU), and 2 patients with fatal outcome were reported, of which 1 was treated at a PICU (Supplementary Table 2).

\section{Characteristics of Patients with Specific Varicella-Related Complications (VRCs)}

Specific complications in varicella patients (VRCs) were reported in 954 of 1263 hospitalized children (75.5\%; Table 1); of these 518 (54.3\%) were male. Demographic characteristics of children with VRCs were comparable to the $309(24.5 \%)$ children without specific VRCs. Children aged $<5$ years made up the largest group in patients either with or without a specific VRC $(69.3 \%$ vs. $63.1 \%, p=0.114)$, whereas the number of children aged between 10 and 16 years was lowest for both categories (5.6\% of patients with VRC vs. $7.4 \%$ of patients without VRC). Interestingly, the proportion of children with an underlying medical condition was significantly lower in children with VRC than in children without VRC $(17.7 \%$ vs. $32.7 \%$, $p<0.001$ ), mainly because of a higher proportion of children with malignancies/disorders of the immune system in the group without VRC. Median duration of hospital stay was longer in children with VRC than in those without VRC ( 4 days vs. 2 days; $p<0.001$ ). The main reason for hospital admission in children with VRC was the varicella infection $(92.7 \%$ with a main diagnostic ICD10 code for varicella, B01.0-B01.9) compared with $64.1 \%(p<0.001)$ in children without VRC.

\section{Types of Varicella-Related Complications (VRCs)}

The most frequent specific VRCs were gastrointestinal complications in $339(26.8 \%)$ of the 1263 varicella patients (Table 2), including mainly patients with dehydration $(18.0 \%$ of 1263) and enteritis/gastroenteritis (11.1\%). Neurologic complications were reported in 228 $(18.1 \%)$ children; most frequent were febrile convulsion $(6.6 \%)$, encephalitis/meningitis $(5.3 \%)$, syncope $(2.4 \%)$, and cerebral convulsions (2.3\%). A varicella-related skin complication occurred in 178 (14.1\%) children; most frequent were dermatitis/eczema $(5.1 \%)$, skin and soft tissue infections (2.9\%), and skin abscesses (2.8\%). In 21 of $217(9.7 \%)$ children with skin complications, secondary bacterial skin infections were reported (Staphylococcus sp. in 11 and Streptococcus sp. in 10 children). Complications related to the upper respiratory tract (URT) including the ears/nose/throat and eyes affected 190 children (15.0\%). The lower respiratory tract (LRT) was affected in 160 (12.7\%) children; $6.2 \%$ had pneumonia, $5.1 \%$ bronchitis, $1.8 \%$ respiratory failure, and $1.7 \%$ pleural effusion/pyothorax. Reported co-infecting bacterial pathogens in children with LRT were Streptococcus spec. (6 children), Mycoplasma pneumoniae (3), Staphylococcus spec. (1), Haemophilus influenzae (1), and Klebsiella pneumoniae (1). Reported co-infecting respiratory viruses were respiratory syncytial virus (RSV) (9) and influenza virus (1). In 26 (2.1\%) children a confirmed or suspected invasive bacterial infection was reported: 18 (1.4\%) had sepsis, 8 
Table 1 Characteristics of 1263 children with varicella-related hospitalization (VRH), with and without specific varicellarelated complications (VRCs); Bavaria, 2005-2011

\begin{tabular}{|c|c|c|c|c|}
\hline & $\begin{array}{l}\text { All children hospitalized } \\
\text { with varicella } \\
\text { (VRH) } \\
N=1263 \\
n(\%) \text { or median (IQR) }\end{array}$ & $\begin{array}{l}\text { Hospitalized varicella } \\
\text { patients with specific } \\
\text { complications (VRC) } \\
N=954 \\
n(\%) \text { or median (IQR) }\end{array}$ & $\begin{array}{l}\text { Hospitalized varicella } \\
\text { patients without } \\
\text { specific complications } \\
N=309 \\
n(\%) \text { or median (IQR) }\end{array}$ & $p$ value $^{\mathrm{a}}$ \\
\hline \multicolumn{5}{|l|}{ Demographic data } \\
\hline Gender male & $689(54.6)$ & $518(54.3)$ & $171(55.3)$ & 0.793 \\
\hline Age (years) & $3.0(1.0-5.0)$ & $3.0(1.0-5.0)$ & $4.0(1.0-5.5)$ & 0.111 \\
\hline \multicolumn{5}{|l|}{ Age groups } \\
\hline $0-4$ years & $856(67.8)$ & $661(69.3)$ & $195(63.1)$ & 0.114 \\
\hline $5-9$ years & $331(26.2)$ & $240(25.2)$ & $91(29.4)$ & \\
\hline $10-16$ years & $76(6.0)$ & $53(5.6)$ & $23(7.4)$ & \\
\hline \multicolumn{5}{|l|}{ Underlying chronic conditions ${ }^{\mathrm{b}}$} \\
\hline $\begin{array}{l}\text { At least one underlying } \\
\text { medical condition }\end{array}$ & $270(21.4)$ & $169(17.7)$ & $101(32.7)$ & $<0.001^{* * *}$ \\
\hline $\begin{array}{l}\text { Malignancies/hematologic } \\
\text { disorder/disorders of the } \\
\text { immune system }\end{array}$ & $113(8.9)$ & $64(6.7)$ & $49(15.9)$ & $<0.001^{* * *}$ \\
\hline Neurologic disorder & $48(3.8)$ & $30(3.1)$ & $18(5.8)$ & $0.039^{*}$ \\
\hline $\begin{array}{l}\text { Failure to thrive/developmental } \\
\text { disorder/preterm birth }\end{array}$ & $34(2.7)$ & $25(2.6)$ & $9(2.9)$ & 0.840 \\
\hline $\begin{array}{l}\text { Cardiovascular/pulmonary } \\
\text { disorders }\end{array}$ & $32(2.5)$ & $26(2.7)$ & $6(1.9)$ & 0.537 \\
\hline Metabolic disorders & $28(2.2)$ & $20(2.1)$ & $8(2.6)$ & 0.657 \\
\hline Ear/nose/throat/eye & $20(1.6)$ & $17(1.8)$ & $3(1.0)$ & 0.436 \\
\hline Congenital malformation & $10(0.8)$ & $8(0.8)$ & $2(0.6)$ & 1.000 \\
\hline Genitourinary disorders & $8(0.6)$ & $5(0.5)$ & $3(1.0)$ & 0.413 \\
\hline Syndromal disease & $7(0.6)$ & $5(0.5)$ & $2(0.6)$ & 0.682 \\
\hline Other comorbidity & $63(5.0)$ & $39(4.1)$ & $24(7.8)$ & $0.015^{*}$ \\
\hline \multicolumn{5}{|l|}{ Hospital stay and outcome } \\
\hline $\begin{array}{l}\text { Varicella infection/complication } \\
\text { main reason for hospital } \\
\text { admission (= main } \\
\text { diagnostic code) }\end{array}$ & $1082(85.7)$ & $884(92.7)$ & $198(64.1)$ & $<0.001^{* * *}$ \\
\hline $\begin{array}{l}\text { Duration of hospital stay } \\
\text { (days) }\end{array}$ & $3.0(2.0-6.0)$ & $4.0(2.0-6.0)$ & $2.0(1.7-4.0)$ & $<0.001^{* * *}$ \\
\hline $\begin{array}{l}\text { Complex intensive care } \\
\text { treatment }\end{array}$ & $5(0.4)$ & $5(0.5)$ & $0(0.0)$ & 0.343 \\
\hline Fatalities & $2(0.2)$ & $2(0.2)$ & $0(0.0)$ & 1.000 \\
\hline
\end{tabular}

${ }^{* * *}$ Significant at $0.1 \%$ level; ${ }^{* *}$ significant at $1 \%$ level; ${ }^{*}$ significant at $5 \%$ level

${ }^{a} p$ value for comparison of children hospitalized with varicella with and without a specific complication; Pearson's Chi ${ }^{2}$ or Fisher's exact test as appropriate and Mann-Whitney $U$ test for continuous variables

${ }^{\mathrm{b}}$ Multiple nominations possible 
Table 2 Varicella-associated complications (VRC) in 954 (76\%) of 1263 hospitalized children; Bavaria, 2005-2011

\begin{tabular}{|c|c|c|}
\hline Complication category & $\begin{array}{l}\text { Number of diagnoses } \\
N \text { (\% of } 1263 \text { patients) }\end{array}$ & $\begin{array}{l}\text { Number of patients } \\
N \text { (\% of } 1263 \text { patients) }\end{array}$ \\
\hline Gastrointestinal complication & $433(34.3)$ & $339(26.8)$ \\
\hline Dehydration & $227(18.0)$ & \\
\hline Enteritis/gastroenteritis & $140(11.1)$ & \\
\hline Constipation & $17(1.3)$ & \\
\hline Other diagnoses & $49(3.9)$ & \\
\hline Neurologic & $271(21.5)$ & $228(18.1)$ \\
\hline Febrile convulsion & $83(6.6)$ & \\
\hline Encephalitis/meningitis & $67(5.3)$ & \\
\hline Syncope & $30(2.4)$ & \\
\hline Cerebral convulsion & $29(2.3)$ & \\
\hline Facial nerve palsy & $8(0.6)$ & \\
\hline Cerebral vasculitis/infarction & $4(0.3)$ & \\
\hline Other diagnoses & $50(4.0)$ & \\
\hline Skin & $217(17.2)$ & $178(14.1)$ \\
\hline Dermatitis/eczema/skin eruption & $64(5.1)$ & \\
\hline Phlegmon & $36(2.9)$ & \\
\hline Abscess & $35(2.8)$ & \\
\hline Skin complication due to specific co-infecting pathogen & $21(1.7)$ & \\
\hline Impetigo & $16(1.3)$ & \\
\hline Urticaria/erythema & $15(1.2)$ & \\
\hline Other diagnoses & $30(2.4)$ & \\
\hline $\begin{array}{l}\text { Upper respiratory tract (URT), ear, nose and throat } \\
\text { (ENT), eye }\end{array}$ & $232(18.4)$ & $190(15.0)$ \\
\hline Otitis & $51(4.0)$ & \\
\hline Conjunctivitis/other affection of conjunctiva & $41(3.2)$ & \\
\hline Acute URT infection, unspecified & $40(3.2)$ & \\
\hline Tonsillitis & $35(2.8)$ & \\
\hline Laryngitis/tracheitis/laryng. spasm & $21(1.7)$ & \\
\hline Other diagnoses & $44(33.5)$ & \\
\hline Lower respiratory tract $(\mathrm{LRT})$ & $197(15.6)$ & $160(12.7)$ \\
\hline Pneumonia & $78(6.2)$ & \\
\hline Bronchitis & $64(5.1)$ & \\
\hline
\end{tabular}


Table 2 continued

Complication category

$\begin{array}{ll}\begin{array}{l}\text { Number of } \\ \text { diagnoses } N \text { (\% of } 1263\end{array} & \begin{array}{l}\text { Number of } \\ \text { patients } N \text { (\% of } 1263 \\ \text { patients) }\end{array} \\ \text { patients) }\end{array}$

Respiratory failure

$23(1.8)$

Pleural effusion/pyothorax

$22(1.7)$

Other diagnoses

$10(0.8)$

Hematologic complications

$57(4.5)$

$44(3.5)$

Thrombocytopenia

$26(2.1)$

Anemia

$15(1.2)$

Other diagnoses

16 (1.3)

Systemic bacterial

35 (2.8)

$26(2.1)$

Sepsis

$18(1.4)$

Osteomyelitis

$8(0.6)$

SIRS

$5(0.4)$

Necrotizing fasciitis

$2(0.2)$

Other diagnoses

$2(0.2)$

Coagulation and sequelae

$22(1.7)$

$21(1.7)$

Reactive arthritis

$9(0.7)$

Other complications

$312(24.3)$

Feeding problems

$172(13.6)$

Kidney and urinary tract

$27(2.1)$

Cardiac complications

$21(1.7)$

Other diagnoses

$92(7.3)$

Multiple nominations per patient possible

(0.6\%) osteomyelitis, $5(0.4 \%)$ systemic inflammatory response syndrome (SIRS), and $2(0.2 \%)$ necrotizing fasciitis. In children with sepsis, seven were diagnosed with co-infecting Streptococcus species (including four with Streptococcus group A and two with $S$. pneumoniae) and four with Staphylococcus species (including three with $S$. aureus). Varicella-specific hematologic complications occurred in 44 (3.5\%) children. Coagulation disorders and related sequelae were reported in $21(1.7 \%)$ children and reactive arthritis in $9(0.7 \%)$. The category 'other complications' included feeding problems (172,
$13.6 \%)$ and kidney and urinary tract complications $(27,2.1 \%)$ as the most frequent.

\section{Annual Rates of Varicella-Related Complications (VRCs)}

During the first year of observation (2005), on average 6.7 [95\% confidence interval (CI): 5.1-8.3] patients with any specific VRC were recorded per participating hospital. Supplementary Table 1 provides information on the number of patients with varicella-related hospitalizations and complication categories 
including the respective rates per hospital and year with confidence intervals. In 2006, the highest average number of patients with VRC was recorded (8.6; 95\% CI: 6.7-10.4). During the following years, average numbers of VRC patients decreased continuously, from 8.0 (95\% CI: 6.2-9.7) in 2007 to 5.2 (95\% CI: 3.9-6.4) in 2008, 3.0 (95\% CI: 2.1-3.8) in 2009, 2.5 (95\% CI: $1.5-3.6)$ in 2010 to 1.5 (95\% CI: $0.8-2.3$ ) in 2011. Overall, VRCs declined significantly by $76.9 \%$ ( $p=0.006$ ) from 2005 to 2011 , with the highest reduction of average cases per hospital and year in children aged $<5$ years by $89.7 \%$ from 5.3 (95\% CI: 4.0-6.6) in 2005 to 0.5 (95\% CI: $0.1-0.9 ; p=0.001)$ in 2011. VRCs in children aged 5-9 years were reduced by $45.1 \%$ from 1.2 (95\% CI: 0.7-1.8) in 2005 to 0.7 (95\% CI: $0.0-2.0 ; p=0.109)$. Only few patients aged 10-16 years were reported each year, with average patient numbers of $0.1 \quad(95 \% \mathrm{CI}$ : $0.0-0.3$ ) in 2005 and 0.3 (95\% CI: 0.1-0.5; $p=0.923)$ in 2011 .

The annual rates for the different types of VRC per hospital and per year are presented in Fig. 1. All the main VRC categories decreased significantly during the 2005 to 2011 observation period. Gastrointestinal complications decreased by $78.0 \%$ from an average patient number per hospital of 2.1 (95\% CI: $1.4-2.8 ; 60$ patients per 29 hospitals $)$ to $0.5(95 \% \mathrm{CI}$ : 0.2-0.7; 10 patients per 22 hospitals) ( $p=0.026$ ), neurologic complications by $64.5 \%$ from 1.8 (95\% CI: $1.2-2.4 ; 52$ patients per 29 hospitals) to 0.6 (95\% CI: $0.3-1.0 ; 14$ patients per 22 hospitals) $(p<0.001)$, and skin complications by $81.2 \%$ from 1.4 (95\% CI: $0.9-2.0 ; 42$ patients per 29 hospitals) to $0.3(95 \% \mathrm{CI}$ $0.0-0.6$; 6 patients per 22 hospitals) $(p=0.006)$. Complications of the upper respiratory tract decreased by $96.8 \%$ from 1.4 (95\% CI: 0.9-2.0; 41 patients per 29 hospitals) to 0.0 (95\% CI: $0.0-0.1$; 1 patient per 22 hospitals) $(p=0.006)$ and of the lower respiratory tract by $90.1 \%$ from 1.4 (95\% CI: $0.9-1.8$; 40 patients per 29 hospitals) to 0.1 (95\% CI: $0.0-0.4 ; 3$ patients per 22 hospitals $) \quad(p=0.003)$. The category 'other complications' decreased by $85.7 \%$ from 1.3 (95\% CI 0.7-1.8; 37 patients per 29 hospitals) to 0.2 (95\% CI 0.0-0.4; 4 patients per 22 hospitals) $(p=0.050)$. Hematologic and systemic bacterial complications, coagulation/sequelae, and reactive arthritis also showed lower complication rates per hospital in 2011 compared with 2005, but the numbers were too low for formal trend analyses. Despite the overall decreasing trend from 2005 to 2011, a conspicuously higher

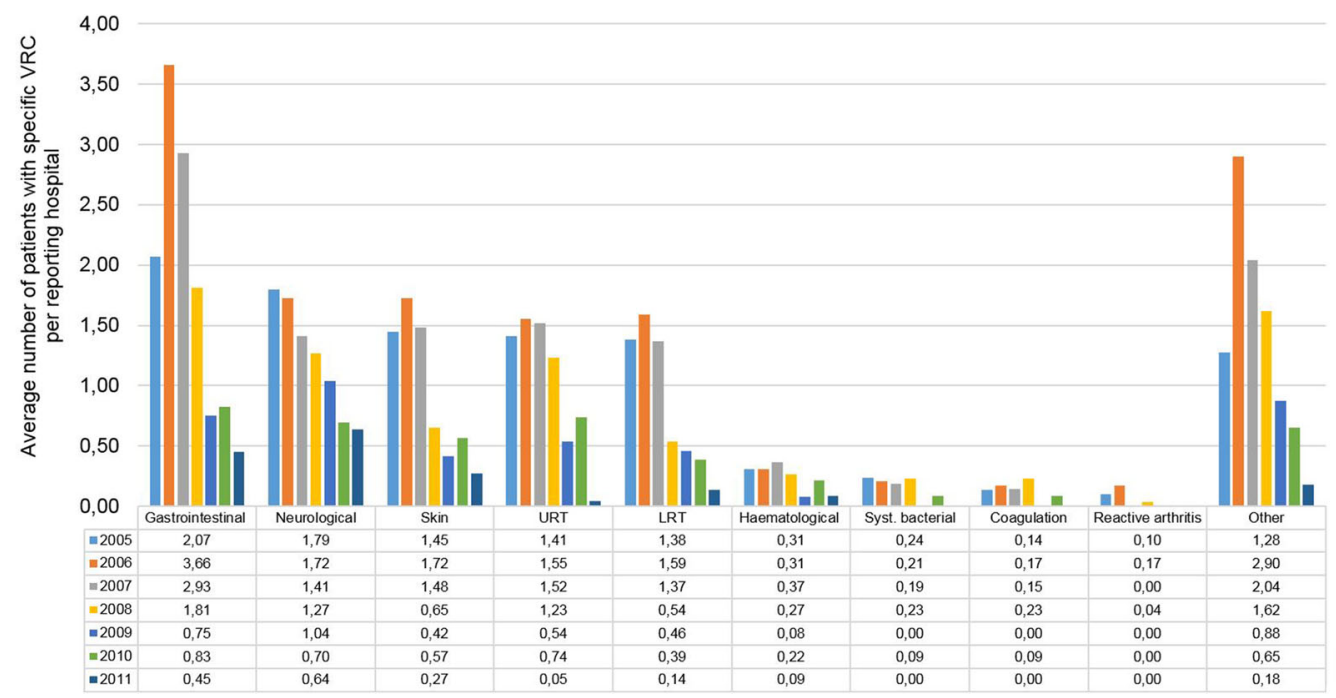

Fig. 1 Change in the rate of varicella-related complications (VRCs) in 954 children in 22-29 participating hospitals from 2005 to 2011; average numbers per reporting hospital are provided per year. Multiple nominations of a patient in different VRC categories were possible. Patients with more than one diagnosis within a VRC category were listed only once per category 
average number of patients per hospital was observed in 2006 and 2007 for the categories 'gastrointestinal complications' and 'other complications' (mainly feeding problems) compared with all other years.

\section{Varicella-Related Complications in Immunocompromised Children}

A subgroup of $93(7.4 \%)$ of the 1263 children with VRH was classified as immunocompromised (Table 3). They were older at hospital admission compared with 1170 immunocompetent children (median age 4 years, IQR: 2.0-6.0 vs. 3 years, IQR: $1.0-5.0 ; p=0.006$ ). Varicella infection was less often the primary diagnosis for hospital admission than in immunocompetent children $(54.8 \%$ vs. to
$88.1 \%, p<0.001)$, and their median hospital stay duration was 2 days longer ( 5 days, IQR: $3.5-9.0$ vs. 3 days, IQR: $2.0-6.0 ; p<0.001)$. One immunocompromised child died (Supplementary Table 2 ). The proportion of immunocompromised children with a specific VRC was lower than in immunocompetent children (51.6\% vs. $77.4 \%, p<0.001)$.

Regarding specific VRCs, immunocompromised children were significantly more frequently reported to have hematologic complications $(20.4 \%$ vs. $2.1 \%, p<0.001)$, systemic bacterial infections $(6.5 \%$ vs. $1.7 \%$, $p=0.009$ ), and coagulation disorders and related sequelae $(5.4 \%$ vs. $1.4 \%, p=0.015)$ than immunocompetent children (Table 4). In contrast, the proportion of gastrointestinal complications was lower in immunocompromised

Table 3 Characteristics of 1263 children with varicella-related hospitalization (VRH) by immune status (Bavaria, 2005-2011)

$\begin{array}{lll}\text { Immunocompromised } & \text { Immunocompetent } & p \text { value }^{\mathrm{a}} \\ \text { children } & \text { children } \\ N=93 & N=1170 \\ n(\%) \text { or median }(\mathrm{IQR}) & n(\%) \text { or median } \\ & (\mathrm{IQR})\end{array}$

Demographic data

\begin{tabular}{|c|c|c|c|}
\hline Gender male & $44(47.3)$ & $645(55.1)$ & 0.089 \\
\hline Age (years) & $4.0(2.0-6.0)$ & $3.0(1.0-5.0)$ & $0.006^{* *}$ \\
\hline \multicolumn{4}{|l|}{ Age groups } \\
\hline $0-4$ years & $58(62.4)$ & $798(68.2)$ & \multirow[t]{3}{*}{0.493} \\
\hline $5-9$ years & $29(31.2)$ & $302(25.8)$ & \\
\hline $10-16$ years & $6(6.5)$ & $70(6.0)$ & \\
\hline \multicolumn{4}{|l|}{ Hospital stay and outcome } \\
\hline With varicella-related complication & $48(51.6)$ & $906(77.4)$ & $<0.001^{* * *}$ \\
\hline $\begin{array}{l}\text { Varicella infection/complication main reason for } \\
\text { hospital admission }\end{array}$ & $51(54.8)$ & $1031(88.1)$ & $<0.001^{* * *}$ \\
\hline Duration of hospital stay (days) & $5.0(3.5-9.0)$ & $3.0(2.0-6.0)$ & $<0.001^{* * *}$ \\
\hline Complex intensive care treatment & $0(0.0)$ & $5(0.4)$ & 0.682 \\
\hline Fatalities & $1(1.1)$ & $1(0.1)$ & 0.142 \\
\hline
\end{tabular}

${ }^{* * *}$ Significant at $0.1 \%$ level, ${ }^{* *}$ significant at $1 \%$ level, ${ }^{*}$ significant at $5 \%$ level

a $p$ value for comparison of children hospitalized with varicella with and without a specific complication; Pearson's Chi ${ }^{2}$ or Fisher's exact test as appropriate and Mann-Whitney $U$ test for continuous variables 
Table 4 Varicella-related complications (VRCs) in immunocompromised and immunocompetent children hospitalized in Bavaria between January 2005 and December 2011

\begin{tabular}{|c|c|c|c|}
\hline & $\begin{array}{l}\text { VRC in immunocompromised } \\
\text { patients } \\
N=93 \\
n(\%)\end{array}$ & $\begin{array}{l}\text { VRC in immunocompetent } \\
\text { patients } \\
N=1170 \\
n(\%)\end{array}$ & $p$ value $^{\mathrm{a}}$ \\
\hline At least one complication & $48(51.6)$ & $906(77.4)$ & $<0.001^{* * *}$ \\
\hline Gastrointestinal complication & $15(16.1)$ & $324(27.7)$ & $0.015^{*}$ \\
\hline Neurologic & $4(4.3)$ & $224(19.1)$ & $<0.001^{* * *}$ \\
\hline Skin & $7(7.5)$ & $171(14.6)$ & 0.063 \\
\hline URT, ENT, eye & $5(5.4)$ & $185(15.8)$ & $0.004^{* *}$ \\
\hline LRT & $7(7.5)$ & $153(13.1)$ & 0.145 \\
\hline Hematologic complications & $19(20.4)$ & $25(2.1)$ & $<0.001^{* * *}$ \\
\hline Systemic bacterial & $6(6.5)$ & $20(1.7)$ & $0.009^{* *}$ \\
\hline Coagulation and sequelae & $5(5.4)$ & $16(1.4)$ & $0.015^{*}$ \\
\hline Reactive arthritis & $1(1.1)$ & $8(0.7)$ & 0.499 \\
\hline Other complications & $22(23.7)$ & $236(20.2)$ & 0.424 \\
\hline
\end{tabular}

Patients could appear in more than one complication category, but only once per category

${ }^{* * *}$ Significant at $0.1 \%$ level, ${ }^{* *}$ significant at $1 \%$ level, ${ }^{*}$ significant at $5 \%$ level

a Two-sided $p$ value for comparison of complications in immunocompromised and immunocompetent children hospitalized with varicella; Pearson's $\mathrm{Chi}^{2}$ or Fisher's exact test as appropriate

children (16.1\% vs. $27.7 \%, p=0.015)$ as well as infections of the URT $(5.4 \%$ vs. $15.8 \%$, $p=0.004)$ and neurologic complications (4.3\% vs. $19.1 \%, p<0.001)$.

The average number of immunocompromised children with VRC decreased by $86.8 \%$ from 0.3 to 0.4 per hospital and year in 2005-2008 to 0.1-0.05 in 2009-2011.

\section{DISCUSSION}

The ICD-10 surveillance in Bavarian hospitals conducted from 2005 to 2011 included the majority of the Bavarian pediatric clinics (annually $61-78 \%)$. Clinical data were available for 1263 children with VRH, including 954 (75.5\%) children with specific VRC. This proportion of children with VRC was similar to other studies in European countries [20-24]. Descriptions of specific VRC types in hospitalized children are available from many countries, but were often limited by the monocentric design and low patient numbers, whereas our multicenter study provided solid data from 22 to 29 pediatric hospitals. Furthermore, it is the first study to describe a relevant impact of UVV simultaneously for the various types of VRC.

The incidence of the various types of VRC varies widely among studies from different countries. This is probably due to divergence in sociodemographic aspects and health care systems [25] as well as differences regarding data sources, data collection methodology, diverging definitions of diagnoses allocated to specific VRC categories, presence of UVV programs, and pre-vaccination $[1,20,22,24,26-29]$ or postvaccination [19, 30-32] periods observed. In Germany, the present study from the post-vaccination period showed lower proportions of neurologic (18\% vs. $25 \%)$ [16] and skin complications ( $14 \%$ vs. $23 \%$ ) but higher proportions of gastrointestinal complications ( $27 \%$ vs. $15 \%)$ compared with the pre-vaccination period [1]. 
Although gastrointestinal complications were the most frequent VRCs during most study years, they showed a conspicuous peak in 2006, a year with an exceptionally strong rotavirus season in Germany [33]. Hence, some of the children with varicella might have been co-infected as the varicella virus and rotavirus show a similar seasonal peak, and both affect mainly children $<5$ years of age. Nevertheless, similarly high rates $(23 \%)$ of patients with gastrointestinal VRC were observed in one of the largest studies on VRC from Canada [19]. Regarding skin complications, our results were in the typical range of $15-25 \%$ described by a recent meta-analysis [34]. Furthermore, rates of rare VRC types and for single VRCs corresponded well with other reports from other large studies.

A high impact of UVV with increasing vaccination coverage on VRH incidence has been shown by a multitude of studies in various countries [35-44], but only single studies addressed the impact of UVV on specific types of VRC [19, 31, 45]. Corresponding to the decrease of VRH incidence in Bavaria following UVV [16], during the 7-year period our study showed a significant overall decrease of VRCs by $76.9 \%$, with the main impact on children < 5 years of age.

During the first 3 years of observation, vaccination coverage in the Bavarian population had only increased slowly because of a delay in reimbursement regulations, and VRH remained largely on the pre-vaccination level, with some variation in strength between varicella seasons $[12,14,15]$. Thus, the main impact on VRCs was seen after 2007, with a large decrease observed in the most frequent VRC categories, but also evident for more rare VRC types. Upper respiratory tract VRCs almost disappeared during the observation period. Of note, neurologic complications and lower respiratory tract infections (both usually requiring longer hospital stay) also showed a reduction of $64.5 \%$ and $90.1 \%$, respectively.

A recent literature review summarized the annual societal costs of varicella in the prevaccination era at 187.5 million euros, of which $18 \%$ were direct medical costs [46]. Hospitalizations due to (severe) varicella complications are the main contributors to the direct medical costs of varicella [47]. For Europe, it has been estimated that about 18,200 to 23,500 VRHs occur each year, the majority in children [4]. Thus, the decrease observed in both frequent and severe VRCs due to UVV suggested a considerable reduction not only of direct medical costs but of societal costs as well.

During the 7-year observation period, we found some decline of VRHs in immunocompromised children, suggesting herd protection effects, but analyses were limited by the low patient numbers. The analyzed data sets did not contain information regarding possible preemptive use of acyclovir. Nevertheless, about half of the immunocompromised children with varicella were admitted without a specific VRC. Hence, it is likely that these VRHs were preventive measures rather than indicated because of a severe course of varicella disease. Although VRCs occurred less frequently, their overall severity was higher in immunocompromised patients, with a higher occurrence of severe bacterial and hematologic complications. Neurologic complications occurred less frequently in immunocompromised patients, similarly as observed in our pre-vaccination study [1]. For the subgroup of oncologic patients, differences in the frequencies of specific VRCs were discussed previously [18].

Two fatal cases occurred, both in children with severe chronic conditions, one of them explicitly attributed to a diagnosis of varicella pneumonia. One child was aged $<11$ months and therefore not indicated yet for varicella vaccination. In the other child, varicella vaccination was contraindicated. Children with contraindications or newborn/infants are likely to benefit from indirect vaccination effects in populations with high vaccination coverage.

Limitations of this study include lack of information on (permanent) sequelae for children with VRC. Nevertheless, as the overall numbers of VRC decreased, it is likely that the rate of (permanent) sequelae attributed to varicella decreased correspondingly to the increasing vaccination rates. The hospital databases did not include information on varicella vaccination, and therefore we could not identify possible varicella breakthrough cases. However, breakthrough varicella cases usually have a 
milder course of disease than in unvaccinated children $[35,48]$ and therefore rarely result in hospitalization. A recent literature review outlined that only about $0-4 \%$ of VRHs were breakthrough varicella cases, based on results from 12 studies in 9 countries [49]. Available treatment data were limited and not sufficiently detailed to evaluate treatment effects during the course of varicella disease. Furthermore, verification of diagnoses and coding via medical record review was not feasible in our study, which is a previously discussed limitation of pseudonymized hospital discharge-based data $[1,16,36]$. This may potentially lead to overestimation of specific VRCs (including children with multiple hospital admissions) or underestimation (children with late-stage complications not attributed to the varicella infection during the allocation of ICD-10 codes).

\section{CONCLUSION}

In the first 7 years following the introduction of UVV in Germany, we observed a substantial decline in VRC-about $76.9 \%$ overall-in both previously healthy and immunocompromised children of all age groups, but this was especially strong in children $<5$ years of age. The impact affected all types of VRCs, with the highest reductions for VRCs of the respiratory tract.

\section{ACKNOWLEDGEMENTS}

Funding. The 'Bavarian Varicella Surveillance Project' was supported by an unrestricted research grant from GlaxoSmithKline (GSK) Vaccines (Rixensart, Belgium) from 2005 to 2011. We acknowledge support for the Rapid Service Fee by the Deutsche Forschungsgemeinschaft and Open Access Publication Fund of Bielefeld University.

Authorship. All authors meet the International Committee of Medical Journal Editors (ICMJE) criteria for authorship for this article, take responsibility for the integrity of the work as a whole, and have given their approval for this version to be published.

Authorship Contributions. Andrea Streng, Veit Grote, and Johannes G. Liese developed the study. Andrea S treng and Johannes G. Liese supervised the study. Andrea Streng, Christine Hagemann, and Johannes G. Liese analyzed the data and interpreted the results. Christine Hagemann drafted the manuscript, and Veit Grote and Alexander Krämer provided valuable input regarding the analysis.

Disclosures. Andrea Streng received further research grants, support for conference attendance, and honoraria for expert meetings from both manufacturers of the varicella vaccines, GSK and Sanofi Pasteur MSD, and from manufacturers of other vaccines. Johannes G. Liese received further research grants, support for conference attendance, and honoraria for expert meetings from both manufacturers of the varicella vaccines, GSK and Sanofi Pasteur MSD, and from manufacturers of other vaccines. Christine Hagemann, Alexander Krämer, and Veit Grote declare no conflict of interest.

Compliance with Ethics Guidelines. Approval was obtained from the Bavarian Data Protection Office (Munich) and the Ethics Committees of the Medical Faculties at the University Hospitals in Munich and Würzburg. The participating hospitals reported pseudonymized data.

Data Availability. The datasets generated during and/or analyzed during the current study are not publicly available because of data protection regulations and contracts with the participating hospitals including guarantees to all participants that individual patient data would be analyzed solely by the investigators at the Department of Pediatrics, University Hospital of Würzburg, and would not be forwarded to any third party.

Open Access. This article is distributed under the terms of the Creative Commons Attribution-NonCommercial 4.0 International License (http://creativecommons.org/licenses/ 
by-nc/4.0/), which permits any noncommercial use, distribution, and reproduction in any medium, provided you give appropriate credit to the original author(s) and the source, provide a link to the Creative Commons license, and indicate if changes were made.

\section{REFERENCES}

1. Liese JG, Grote V, Rosenfeld E, Fischer R, Belohradsky $\mathrm{BH}$, von Kries, Rüdiger and the ESPED Varicella Study Group. The burden of varicella complications before the introduction of routine varicella vaccination in Germany. Pediatr Infect Dis J. 2008;27:125-9.

2. Borte M, Heininger U, Liese JG, Sauerbrei A, Siedler A. Varizellen Zoster. In: Deutsche Gesellschaft für Pädiatrische Infektiologie e.V. (DGPI), editor. DGPI Handbuch: Infektionen bei Kindern und Jugendlichen. 6th ed. s.l.: Georg Thieme Verlag KG. 2013;582-7.

3. Robert Koch-Institut. Ratgeber Infektionskrankheiten: 20. Folge: Varizellen, Herpes Zoster. Epid Bull. 2000;46:365-9.

4. Riera-Montes M, Bollaerts $\mathrm{K}$, Heininger U, Hens $\mathrm{N}$, Gabutti G, Gil A, et al. Estimation of the burden of varicella in Europe before the introduction of universal childhood immunization. BMC Infect Dis. 2017;17:353.

5. Bozzola E, Bozzola M. Varicella complications and universal immunization. J Pediatr (Rio J). 2016;92:328-30.

6. Kalies H, Grote V, Schmitt H-J, von Kries R. Immunisation status of children in Germany: temporal trends and regional differences. Eur J Pediatr. 2006;165:30-6.

7. Wagenpfeil S, Neiss A, Banz K, Wutzler P. Empirical data on the varicella situation in Germany for vaccination decisions. Clin Microbiol Infect. 2004;10:425-30.

8. Grote V, von Kries R, Springer W, Hammersen G, Kreth HW, Liese J. Varicella-related deaths in children and adolescents-Germany 2003-2004. Acta Paediatr. 2008;97:187-92.

9. Robert Koch-Institut. Begründung der STIKO für eine allgemeine Varizellenimpfung. Epid Bull. 2004;49:421-3.

10. Robert Koch-Institut. Begründung einer zweiten Varizellenimpfung im Kindesalter. Epid Bull. 2009;32:328-36.
11. Siedler A, Dettmann M. Hospitalization with varicella and shingles before and after introduction of childhood varicella vaccination in Germany. Hum Vaccin Immunother. 2014;10:3594-600.

12. Hagemann C, Seeger K, Krämer A, Liese JG, Streng A. Entwicklung der Varizellen-Impfraten und mögliche Einflussfaktoren auf die Impfentscheidung der Eltern im Raum München in den Jahren 2009-2011 nach Einführung der allgemeinen Varizellenimpfung. Gesundheitswesen. 2017;79:286-95.

13. Hagemann C, Streng A, Kraemer A, Liese JG. Heterogeneity in coverage for measles and varicella vaccination in toddlers-analysis of factors influencing parental acceptance. BMC Public Health. 2017;17:724.

14. Streng A, Seeger K, Grote V, Liese JG. Varicella vaccination coverage in Bavaria (Germany) after general vaccine recommendation in 2004. Vaccine. 2010;28:5738-45.

15. Streng A, Grote V, Carr D, Hagemann C, Liese JG. Varicella routine vaccination and the effects on varicella epidemiology-results from the Bavarian Varicella Surveillance Project (BaVariPro), 2006-2011. BMC Infect Dis. 2013;13:303.

16. Streng A, Grote V, Rack-Hoch A, Liese JG. Decline of neurologic varicella complications in children during the first seven years after introduction of universal varicella vaccination in Germany, 2005-2011. Pediatr Infect Dis J. 2017;36:79-86.

17. Streng A, Liese JG. Decline of varicella vaccination in German surveillance regions after recommendation of separate first-dose vaccination for varicella and measles-mumps-rubella. Vaccine. 2014;32:897-900.

18. Streng A, Wiegering V, Liese JG. Varicella in pediatric oncology patients in the post-vaccine eraanalysis of routine hospital data from Bavaria (Germany), 2005-2011. Pediatr Hematol Oncol. 2016;33:468-79.

19. Tan B, Bettinger J, McConnell A, Scheifele D, Halperin S, Vaudry W, Law B. The effect of funded varicella immunization programs on varicella-related hospitalizations in IMPACT centers, Canada, 2000-2008. Pediatr Infect Dis J. 2012;31:956-63.

20. Bonhoeffer J, Baer G, Muehleisen B, Aebi C, Nadal D, Schaad UB, Heininger U. Prospective surveillance of hospitalisations associated with varicellazoster virus infections in children and adolescents. Eur J Pediatr. 2005;164:366-70.

21. Bozzola E, Quondamcarlo A, Krzysztofiak A, Pandolfi E, Lancella L, Tozzi A. Haematological 
complications in otherwise healthy children hospitalized for varicella. Vaccine. 2011;29:1534-7.

22. van Lier A, van der Maas NAT, Rodenburg GD, Sanders EAM, de Melker HE. Hospitalization due to varicella in the Netherlands. BMC Infect Dis. 2011;11:85.

23. Blumental S, Sabbe M, Lepage P. Varicella paediatric hospitalisations in Belgium: a 1-year national survey. Arch Dis Child. 2016;101:16-22.

24. Glode Helmuth I, Broccia MD, Glenthøj JP, Harder $\mathrm{K}$, Jensen L, von Linstow M-L, et al. Children hospitalized with varicella in Denmark: sensitivity of the National Patient Register. Pediatr Infect Dis J. 2017;36:31-5.

25. Bozzola E, Gattinara GC, Bozzola M, Mirante N, Masci M, Rossetti C, et al. Varicella associated pneumoniae in a pediatric population. Ital J Pediatr. 2017;43:49.

26. Gowin E, Wysocki J, Michalak M. Don't forget how severe varicella can be-complications of varicella in children in a defined Polish population. Int J Infect Dis. 2013;17:e485-9.

27. Popescu CP, Ceausu E, Florescu SA, Chirita D, Ruta S. Complications of varicella in unvaccinated children from Romania, 2002-2013: a retrospective study. Pediatr Infect Dis J. 2016;35:211-2.

28. Jackson MA, Burry VF, Olson LC. Complications of varicella requiring hospitalization in previously healthy children. Pediatr Infect Dis J. 1992;11:441-5.

29. Miranda-Choque E, Candela-Herrera J, Díaz-Pera J, Farfán-Ramos S, Muñoz-Junes EM, Escalante-Santivañez IR. Varicela complicada en un hospital pediátrico de referencia, Perú 2001-2011. Rev Peru Med Exp Salud Publica. 2013;30:45-8.

30. Marshall HS, McIntyre P, Richmond P, Buttery JP, Royle JA, Gold MS, et al. Changes in patterns of hospitalized children with varicella and of associated varicella genotypes after introduction of varicella vaccine in Australia. Pediatr Infect Dis J. 2013;32:530-7.

31. Arlant LHF, Garcia MCP, Avila Aguero ML, Cashat M, Parellada CI, Wolfson LJ. Burden of varicella in Latin America and the Caribbean: findings from a systematic literature review. BMC Public Health. 2019;19:528.

32. Elbaz M, Paret G, Yohai AB, Halutz O, Grisaru-Soen G. Immunisation led to a major reduction in paediatric patients hospitalised because of the varicella infection in Israel. Acta Paediatr. 2016;105:e161-6.
33. Robert Koch-Institut. Epidemiologie der RotavirusErkrankungen in Deutschland im Zeitraum von 2001 bis 2011. Epid Bull. 2012;44:441-9.

34. Bozzola E, Bozzola M, Krzysztofiak A, Tozzi AE, El Hachem M, Villani A. Varicella skin complications in childhood: a case series and a systematic review of the literature. Int J Mol Sci. 2016;17:688.

35. Baxter R, Ray P, Tran TN, Black S, Shinefield HR, Coplan PM, et al. Long-term effectiveness of varicella vaccine: a 14-year, prospective cohort study. Pediatrics. 2013;131:e1389-96.

36. Davis MM, Patel MS, Gebremariam A. Decline in varicella-related hospitalizations and expenditures for children and adults after introduction of varicella vaccine in the United States. Pediatrics. 2004;114:786-92.

37. Reynolds MA, Watson BM, Plott-Adams KK, Jumaan AO, Galil K, Maupin TJ, et al. Epidemiology of varicella hospitalizations in the United States, 1995-2005. J Infect Dis. 2008;197(Suppl 2):6.

38. Seward JF. Varicella disease after introduction of Varicella Vaccine in the United States, 1995-2000. JAMA. 2002;287(5):606-11.

39. Sheridan SL, Quinn HE, Hull BP, Ware RS, Grimwood K, Lambert SB. Impact and effectiveness of childhood varicella vaccine program in Queensland, Australia. Vaccine. 2017;35:3490-7.

40. Spoulou V, Alain S, Gabutti G, Giaquinto C, Liese J, Martinon-Torres F, Vesikari T. Implementing universal varicella vaccination in Europe: the path forward. Pediatr Infect Dis J. 2019;38:181-8.

41. Varela FH, Pinto LA, Scotta MC. Global impact of varicella vaccination programs. Hum Vaccin Immunother. 2019;15:645-57.

42. García Comas L, Latasa Zamalloa P, Alemán Vega G, Ordobás Gavín M, Arce Arnáez A, Rodero Garduño I, et al. Descenso de la incidencia de la varicela en la Comunidad de Madrid tras la vacunación infantil universal. Años 2001-2015. Aten Primaria. 2018;50:53-9.

43. Heywood AE, Wang H, Macartney KK, McIntyre P. Varicella and herpes zoster hospitalizations before and after implementation of one-dose varicella vaccination in Australia: an ecological study. Bull World Health Organ. 2014;92:593-604.

44. Shah SS, Wood SM, Luan X, Ratner AJ. Decline in varicella-related ambulatory visits and hospitalizations in the United States since routine immunization against varicella. Pediatr Infect Dis J. 2010;29:199-204. 
45. Lopez AS, Zhang J, Brown C, Bialek S. Varicella-related hospitalizations in the United States, 2000-2006: the 1-dose varicella vaccination era. Pediatrics. 2011;127:238-45.

46. Damm O, Witte J, Wetzka S, Prosser C, Braun S, Welte R, Greiner W. Epidemiology and economic burden of measles, mumps, pertussis, and varicella in Germany: a systematic review. Int J Public Health. 2016;61:847-60.

47. Horn J, Damm O, Kretzschmar ME, Karch A, Siedler A, Ultsch B, et al. Mathematische Modellierung der
Effekte des Varizellen-Impfprogramms in Deutschland: Abschlussbericht, Version 1.2. Braunschweig, Bielefeld, Utrecht, Berlin; 16.09.2014.

48. Andrade AL, da Silva Vieira MA, Minamisava R, Toscano CM, Lima Souza MB, Fiaccadori F, et al. Single-dose varicella vaccine effectiveness in Brazil: a case-control study. Vaccine. 2018;36:479-83.

49. Leung J, Broder KR, Marin M. Severe varicella in persons vaccinated with varicella vaccine (breakthrough varicella): a systematic literature review. Expert Rev Vaccines. 2017;16:391-400. 